\title{
Intellectual Capital and Predefined Headings in Swedish Health Care Sector
}

\author{
Annika Terner $^{1}$, and Amra Halilovic ${ }^{2}$ \\ ${ }^{1}$ Uppsala Region, Uppsala and Department of Public Health and Caring Sciences, Uppsala university, Uppsala, Sweden \\ ${ }^{2}$ Dalarna County Council, Falun, Sweden
}

\begin{abstract}
The heavily decentralized Swedish health care sector is facing massive challenges, e.g. to even out differences in health care performance. Intellectual Capital can partly be used to explain these differences. In the research field it is difficult to find contributions regarding the study of intellectual capital management in the health care sector and there is also a lack of studies on semantic interoperability. It is semantic interoperability which allows the right information to be available to the right people at the right time across products and organizations. Structured and standardized headings can be a tool to enable semantic interoperability. The aim of this article is to argue for predefined headings as intellectual capital and as base for a national shared and standardized terminology in the health care sector. The study shows that there is a lack of national management of predefined headings deployed in both electronic health records and national quality registries. This lack causes multiple documentation which is time-consuming, impacts health professionals' workloads, data quality and partly the performance of health care. We argue that predefined headings can be a base for semantic interoperability and that there is a need for the management of predefined headings on a national level.
\end{abstract}

\section{Introduction}

Sweden, when compared with other countries, produces high quality health care and takes first place in the efficiency index where the overall quality of health care is related to the cost of achieving this quality [1].

The health care sector in Sweden is heavily decentralized with 21 county councils and regions responsible for financing and providing good health care for all inhabitants in the country. The principle of local selfgovernment gives each county council and region the right to design health care services with reference to local conditions. [2]

However, this principle enables differences between county councils and regions in terms of both organizational infrastructure and IT infrastructure. The National Board of Health and Welfare has recently pointed out remarkably large differences between county councils and regions regarding access to health care services, medical results and financial results. [3]

In addition to these differences between county councils and regions, the Swedish health care sector, like health care sectors in other countries, is facing massive challenges: demographic changes, medical and technological advances, growing expectations of citizens, and stablizing financial resources [4-6]. However, as Elg et. al. express; 'financial resources allocated to health care are not expected to increase' [4] p. 102]

The health care sector is a complex system involving different stakeholders: health care professionals, patients, researchers, IT suppliers, government, administrators and others. Health care professionals, such as physicians and nurses, have to work together in order to deliver good quality health care for their patients. Their decisions are dependent on knowledge and it is important that knowledge created by one part is shared with other parts as there is the need 'to deliver the right information, at the right time, to the right person, and in the right format.' [7], p. 497]

The health care sector is a knowledge-intensive sector with valuable assets. This stock of knowledge is defined as intellectual capital (IC) [8]. Chang et. al. describe IC as the knowledge-related intangible assets embedded in an organization [9]. It is widely accepted that IC is a crucial factor for organizational success [10]. Effective management of IC, together with physical capital, contributes to sustainable and competitive advantages [11]. IC is also perceived as a factor which can partly explain variations in the performance of healthcare organizations [8]. 
In the literature, it is difficult to find contributions regarding the study of IC management in the health care sector. The research field has focused mostly on single organizations, for example hospitals. [11-13]

Management of IC in the health care sector faces several challenges; particularly challenging is the lack of integration between the different IT systems and thereby the lack of integrated information [7].

Over the years different solutions of technical interoperabilitet have been invented and implemented. However these solutions are ineffective because they do not solve the lack of semantic interoperability. Semantic interoperability allows the right information to be available to the right people at the right time across products and organisations $[14,15]$.

In a recent study we argued that structured and standardized headings (defining health information similar to physical labels on boxes [16]) can be a tool to enable access to health-related information at the right time, to the right person and in the right format.

\section{Aim}

The aim of this article is to argue that predefined headings are intellectuell capital and therefore can be a base for a national shared and standardized terminology in the health care sector.

\section{Intellectual Capital}

Traditionally IC is described as the stock or sum of knowledge which organizations use for value creation and competitive advantage $[8,17,18]$. There are three different types of IC: human, structural and relational capital, see Figure 1.

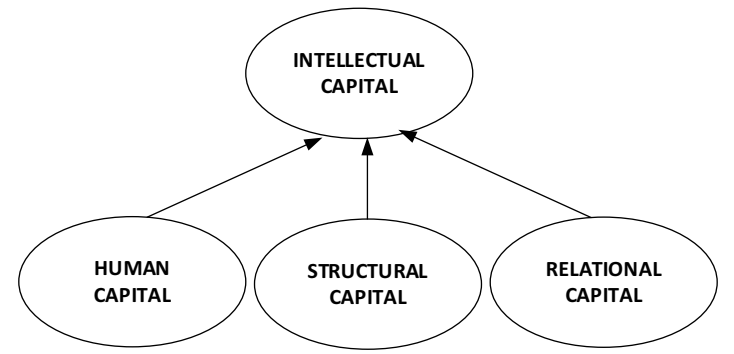

Figure 1: Conceptualisation of Intellectual Capital (after Bontis, N., 1999)

Human capital is defined as the knowledge, skills and experiences owned and utilized by individuals. In the health care context this knowledge is an important factor in achieving high performances [20].

Structural capital, also called organizational capital, is defined as institutionalized knowledge. The individual knowledge is codified, stored and shared. This knowledge together with routines, procedures, IT systems, research and organizational culture constitutes organizational capital. [11]

Relational capital, also called social, is defined as the knowledge available through, derived from, and utilized by networks of relationships. It is the knowledge at group level. [19]

These three types of IC are interdependent and they form the stock of knowledge in an organization [8]. IC is created by individuals and needs to be shared before it becomes knowledge at the group or organizational level [8, $20]$.

According to Nonaka it is important to highlight the distinction between information and knowledge. Information is defined as a flow of messages and knowledge; '...created and organized by the very flow of information, anchored on the commitment and beliefs of its holder. This understanding emphasizes an essential aspect of knowledge that relates to human action.' [20].

Nonaka's 'Spiral of organizational knowledge creation' explains how tacit and explicit knowledge held by individuals can be transformed, legitimized, enlarged and enriched [20].

\section{Predefined Headings and Electronic Health Records}

Predefined headings are an expression of knowledge-based healthcare. As early as in 1730 criteria for proper documentation of disease progression was the focus in a medical thesis [21]. At the first hospital in Sweden, Serafimerlasarettet in Stockholm, 50 rules governed the health care activities in 1755 . Some of these rules governed the documentation in health records. The documentation should include diagnosis, therapy, cure, surgery, food and disease progression. [22] One hundred years later, at the same hospital, health records were structured by predefined headings; previous diseases, cause of disease, symptoms, diagnosis and prognosis are examples of predefined headings employed in 1851 [22]. In 1984 a structure of predefined headings for a basic health record was introduced to the Swedish health care sector. The structure of predefined headings was developed by physicians and examples of predefined headings include hereditary, previous diseases, hypersensitivity and symptoms. [23]

The health care professionals have defined the headings based on their knowledge and experience of what information is necessary to provide good health care [24].

Previous research has shown that predefined headings are employed to structure health information about patients in electronic health records (EHRs) $[25,26]$. Underneath each predefined heading, the health care professional enters narrative text, one or more predefined statements, or a numeric value.

EHR is defined as an electronic record of health-related information on an individual which conforms to nationally recognized interoperability standards and which can be 
created, managed, and consulted by health care professionals across health care organizations. Healthrelated information means, among others, treatment and discharge summaries, investigation results and reports, prescriptions and health care professional notes. [27]

The primary purpose of EHRs is to support the continuity, efficiency and quality of health care. The information in an EHR is retrospective, concurrent, and prospective [28]. For health care professionals and patients, the EHR represents opportunities in terms of accessible, systematic, and comprehensive patient information. [29]

The EHR is expected to provide information when and where it is needed about the patient [30, 31]. Most EHRs in Sweden are similar to the previous handwritten health records structured by predefined headings in predefined templates [32].

The problem is that each county council and region has their own terminology of predefined headings in their EHRs. The result of a recent study showed that the number of shared and standardized predefined headings in EHRs across three county councils and regions was just $2 \%$ [33]. This means that health information about the same patient cannot be exchanged between county councils and regions. The solution is semantic interoperability, which means that the information is unambiguously understood in content, meaning, and purpose by the receiver $[34,35]$

\section{Predefined Headings and National Quality Registries}

Predefined headings are also employed in National Quality Registries (NQRs). In Sweden, NQRs have a long history. From the beginning, they were created by the individuals who themselves would benefit from them in their professional lives. Today there are about one hundred NQRs in Sweden; examples include the Swedish Hip Arthroplasty Register, National Quality Registry of Stroke and National Diabetes Registry. The NQRs contain individualized data concerning health information about patients. The data is protected by the Patient Data Act [36] and all county councils and regions are recommended to register data in NQRs.

Reports from NQRs are available to health care professionals and managers in county councils and regions [37]. Some NQRs are also freely available to all inhabitants via the Internet. On a national level the reports from NQRs constitute an important input to monitoring and comparing performance of health care among county councils and regions; an example is 'Open Comparison and Assessment' [38].

NQRs are sources of "knowledge of improvement" because they contain aggregated data which, after analysis, can lead to documented evidence for or against e.g. methods and material used in health care. This, in turn, leads to better outcomes for patients. This improvement of knowledge is an important part of knowledge-based health care [33].

Each NQR has defined their headings based on the indicators which are important to follow up for their specialty, e.g. diabetes. The consequence of this is a lack of shared predefined headings across the NQRs, which also indicates a lack of semantic interoperability between NQRs. [33]

\section{Conclusions}

Predefined headings are expressions for health care professionals' knowledge, skills and experiences. When deployed in EHRs the information and knowledge can be shared within the county council or region, and by deployment in NQRs the information and knowledge can be shared among county councils or regions; as a result predefined headings should be regarded as intellectual capital.

There is an assumption that there is semantic interoperabilty between EHRs and NQRs, e.g. that the predefined headings in NQRs are shared with EHRs. However, the fact is that each county council and region has its own terminology of predefined headings in their EHRs and each NQR has its own termninolgy of predefined headings which means a lack of semanic interoperability between EHRs and NQRs.

Thus, there is a lack of national management of predefined headings deployed in both EHRs and NQRs. This lack results in multiple documentation, eg health care professionals must first document in an EHR and then register the same information in another way in a NQR. Consequently this is time-consuming and impacts the workload and data quality and partly the performance of health care.

Over the years different solutions of technical interoperability have been invented and implemented. However these solutions have been ineffective because they do not solve the problem of lack of shared and standardized predefined headings across EHRs and NQRs.

We believe that predefined headings can be a base for a shared and standardized terminology for the health care sector in Sweden and therefore we recommend management of predefined headings on a national level.

\section{References}

1 Sveriges Kommuner och Landsting, Svensk sjukvård $\mathrm{i}$ internationell jämförelse. (Swedish health care in international comparison.), Stockholm(2015).

2 Ministry of Health and Social Affairs, Health and medical care in Sweden, Ministry of Health and Social Affairs, Ed., ed. Stockholm: The Government Offices of Sweden (2011, updated 30 January 2012). 
3 Socialstyrelsen, Öppna jämförelser 2016 - En god vård? Övergripande uppföljning utifrån sex frågor om hälso- och sjukvårdens resultat (Comparisons 2016 - A good health care? Overall follow-up based on six questions about health care results), Stockholm(2017).

4 M. Elg, J. Stenberg, P. Kammerlind, S. Tullberg, J. Olsson, Swedish healthcare management practices and quality improvement work: development trends, Int J Health Care Qual Assur, vol. 24, pp. 101-23 (2011).

5 G. Bronzetti, M. A. Baldini, G. Sicoli, Intellectual Capital Report in the Healthcare Sector: An Analysis of a Case Study, in Handbook of Research on Human Resources Strategies for the New Millennial Workforce, P. O. d. Pablos and R. D. Tennyson, Eds., ed: Business Science Reference (2017).

6 A. Garlatti, M. Massaro, V. Bruni, Intellectual capital evaluation in a health care organization. A case study., presented at the XIX IRSPM Conference, Birmingham (2015).

7 C. El Morr, J. Subercaze, Knowledge management in healthcare, in Handbook of Research on Developments in e-Health and Telemedicine: Technological and Social Perspectives, ed: IGI Global (2010), pp. 490-510.

8 J. M. Evans, A. Brown, G. R. Baker, Intellectual capital in the healthcare sector: a systematic review and critique of the literature, BMC Health Serv Res, vol. 15, p. 556 Dec 15 (2015).

9 S.-C. Chang, S.-S. Chen, J.-H. Lai, The effect of alliance experience and intellectual capital on the value creation of international strategic alliances, Omega, vol. 36, pp. 298-316 (2008).

L. Moore, L. Craig, Intellectual capital in enterprise success: strategy revisited: John Wiley \& Sons (2008).

11 S. Veltri, G. Bronzetti, G. Sicoli, Reporting intellectual capital in health care organizations: Specifics, lessons learned, and future research perspectives, (2011).

12 J. Van Beveren, Does health care for knowledge management?, Journal of knowledge management, vol. 7, pp. 90-95 (2003).

13 D. Jelonek, A. Halilovic, From intangible assets to management of intellectual capital within health care industry. A comparative study between Sweden and Poland, International Journal of Economics and Statistics, vol. 4, (2016).

14 M. P. Stroupe. (2013). What is EHR Interoperability and Why Should I Care? A reference document for Urgent Care and Occupational Health Providers. Available: http://www.nethealth.com/wpcontent/uploads/2013/11/What-is-EHRInteroperability.pdf
M. Schweitzer, A. Hoerbst, Dynamic User Interfaces for Service Oriented Architectures in Healthcare, Stud Health Technol Inform, vol. 228, pp. $795-7$ (2016).

M. Nordman, Överskrift, titel, namn eller rubrik? Några beteckningar i teori och praktik (Caption, title, name or heading? Some indications of the theory and practice), in I terminologins tjänst Festskrift för Heribert Picht på 60-årsdagen, A. Nuopponen, B. Toft, and J. Myking, Eds., ed Vaasa: Vasa universitet (2000), pp. 110-7.

$\mathrm{N}$. Bontis, Managing organizational knowledge by diagnosing intellectual capital: Framing and advancing the state of the field, in The Strategic Management of Intellectual Capital and Organizational Knowledge, N. Bontis and C. W. Choo, Eds., ed New York: Oxford University Press (2002).

M. Subramaniam, M. A. Youndt, The Influence of Intellectual Capital on the Types of Innovative Capabilities, The Academy of Management Journal, vol. 48, pp. 450-463 (2005).

P. Ordóñez de Pablos, Measuring and reporting structural capital: Lessons from European learning firms, Journal of Intellectual Capital, vol. 5, pp. 629-647 (2004).

I. Nonaka, A Dynamic Theory of Organizational Knowledge Creation, Organization Science, vol. 5, pp. 14-37 (1994).

N. Rosén von Rosenstein, De historiis morborum rite consignandis, Harderwijk, (1730).

I. Nilsson, Medicinsk dokumentation genom tiderna (Medical documentation through the ages). Lund: Lunds universitet (2007).

R. Hynninen, B. Wadman, H. Åberg, Att skriva patientjournaler (Writing patient records), 2nd ed. Lund: Studentlitteratur (1984).

A. Terner, H. Lindstedt, M. Pless, K. Sonnander, A Retrospective Analysis of Health, Health Care, and Legal Requirements as Reflected in Predefined Headings in an EHR, e-Journal of Health Informatics vol. 9, (2015).

D. L. Andreen, L. J. Dobie, J. C. Jasperson, T. A. Lucas, C. L. Wubbenhorst, The conversion to electronic hospital notes at Mayo Clinic. Overcoming barriers and challenges, J Healthc Inf Manag, vol. 24, pp. 57-64 Summer (2010).

J. C. Denny, A. Spickard, 3rd, K. B. Johnson, N. B. Peterson, J. F. Peterson, R. A. Miller, Evaluation of a method to identify and categorize section headers in clinical documents, J Am Med Inform Assoc, vol. 16, pp. 806-15 Nov-Dec (2009).

The National Alliance for Health Information Technology, Report to the Office of the National Coordinator for Health Information Technology on 
Defining key health information technology terms, (2008).

28 International Organization for Standardization, Health informatics - Electronic health record Definition, scope and context, (2006).

29 A. Terner, Predefined Headings in a Multiprofessional Electronic Health Record: Professionals' Application, Aspects of Health and Health Care and Correspondence to Legal Requirements, Uppsala universitet, (2014).

30 W. W. Stead, Rethinking electronic health records to better achieve quality and safety goals, Annu Rev Med, vol. 58, pp. 35-47 (2007).

31 C. M. Cusack, Electronic health records and electronic prescribing: promise and pitfalls, Obstet Gynecol Clin North Am, vol. 35, pp. 63-79, ix Mar (2008).

32 A. Terner, H. Lindstedt, K. Sonnander, Predefined headings in a multiprofessional electronic health record system, J Am Med Inform Assoc, vol. 19, pp. 1032-8 Nov-Dec (2012).

33 A. Halilovic, A. Terner, Standardized headings as a foundation for semantic interoperability in EHR, MATEC Web Conf., vol. 76, p. 04001 (2016).

34 Healthcare Information and Management Systems Society. (2005). Interoperability Definition and Background. Approved by HIMSS Board of Directors 06/09/05. Available: http://www.himss.org/sites/himssorg/files/HIMSSo $\mathrm{rg} /$ Content/files/AUXILIOHIMSSInteroperability Defined.pdf

35 European Commission, European Interoperability Framework (EIF) for European public services, European Commission, Ed., ed. Bruxelles, Belgique: European Commission (2010).

36 Patientdatalag (Patient Data Act), Socialdepartementet (2008).

37 Nationella Kvalitetsregister. (2016, 24 March). Swedish National Quality Registries. Available: http://kvalitetsregister.se/englishpages.2040.html

38 Sveriges Kommuner och Landsting. (2016). Öppna jämförelser (Open Comparison and Assessment). Available:

https://skl.se/tjanster/merfranskl/oppnajamforelser. $\underline{275 . h t m l}$ 